\title{
Inhibitory effect of microRNA-27b on interleukin 17 (IL-17)-induced monocyte chemoattractant protein-1 (MCP1) expression
}

\author{
K.D. Huang, Y. Shen, X. Wei, F.Q. Zhang, Y.Y. Liu and L. Ma \\ Clinical Laboratory Department, \\ The First Affiliated Hospital of Zhengzhou University, Zhengzhou, China \\ Corresponding author: Y. Shen \\ E-mail: yanshencn@126.com \\ Genet. Mol. Res. 15 (2): gmr. 15027784 \\ Received October 6, 2015 \\ Accepted December 18, 2015 \\ Published July 15, 2016 \\ DOI http://dx.doi.org/10.4238/gmr.15027784
}

\begin{abstract}
We investigated the effect of microRNA-27b (miR-27b), a gene expression regulatory factor, on the expression of monocyte chemoattractant protein-1 (MCP1) stimulated by interleukin 17 (IL17). After IL-17 had been added to $\mathrm{H} 9 \mathrm{C} 2$ cardiomyocytes, an miR$27 \mathrm{~b}$ mimic was transfected into the H9C2 cells. The mRNA expression levels of miR-27b and MCP1 in the H9C2 cells were detected by SYBR green I fluorescence quantitative reverse transcription polymerase chain reaction. Enzyme-linked immunosorbent assay was used to measure the expression levels of MCP1 protein in the H9C2 cells. The expression of MCP1 mRNA in the H9C2 cells began to increase $2 \mathrm{~h}$ after IL-17 stimulation, reached a peak at $4 \mathrm{~h}$, and then decreased. The MCP1 protein level increased gradually in the $24 \mathrm{~h}$ following IL-17 stimulation. After transfection with the miR-27b mimic, the expression of miR-27b in the $\mathrm{H} 9 \mathrm{C} 2$ cells significantly increased than that in the miRNA negative control group $(\mathrm{P}<0.01)$. The MCP1 mRNA and protein levels in the miR-27b mimic + IL-17 group were significantly reduced than that in the miRNA negative control + IL-17 group $(\mathrm{P}<$ 0.01). miR-27b inhibited IL-17-induced MCP1 expression in the H9C2
\end{abstract}


cells, which demonstrates that treatment with microRNA could alleviate myocardial injury in viral myocarditis.

Key words: H9C2 cardiomyocytes; miR-27b; Interleukin 17; Monocyte chemoattractant protein-1

\section{INTRODUCTION}

Monocyte chemoattractant protein-1 (MCP1) is a chemokine that can be expressed in monocytes, macrophages, and endothelial cells. Research has shown that the expression of MCP1 increases in the serum of patients with acute myocarditis (Fuse et al., 2001). To investigate the role of MCP1 in myocarditis, Kolattukudy et al. (1998) specifically induced the expression of MCP1 in the myocardial tissue of transgenic mice, and found that high expression of MCP1 is closely related to the infiltration of myocardial tissue by lymphocytes, and to cardiac dysfunction. This confirmed that MCP1 plays an important role in myocarditis. In our previous study (Shen et al., 2014), we showed that the degree of myocarditis could be reduced by interfering with the expression of MCP1 using anti-MCP1 monoclonal antibody, which indicated that MCP1 had a significant influence on the development of viral myocarditis (VMC). Mononuclear cell migration mediated by MCP1 is an important mechanism for the damage of myocardial tissue in mice with VMC (Shen et al., 2004), and we found that the mononuclear cells that migrate have a significant cytotoxic effect on normal myocardial cells cultured in vitro (Shen et al., 2009). Thus, MCP1 also plays an important role in autoimmune damage in VMC.

Interleukin 17 (IL-17) is an important inflammatory mediator; it can transfer signals via heteromers comprising IL-1RA and IL-17RC, and can induce a variety of inflammatory cytokines to mediate inflammatory infiltration and tissue damage. IL-17 plays an important role in the inflammatory reaction and in immunological defense (Qiu et al., 2009). Our study also found that IL-17 can upregulate the expression of MCP1 in myocardial cells (Liu et al., 2012). Autoimmune-mediated myocardial pathological change is an important factor for $\mathrm{VMC}$, allowing evolve into dilated cardiomyopathy; $\mathrm{MCP} 1$ is closely related to the occurrence of myocarditis. Therefore, we speculate that reducing the expression of MCP1 may help to improve the prognosis of $\mathrm{VMC}$, while the regulatory mechanism of MCP1 involved in the pathological process of myocarditis also requires further study.

MicroRNA (miRNA) is an important member of the non-coding RNA family, knowledge of which has increased rapidly in recent years. It inhibits the expression of target genes by interacting with a particular area of the 3'-untranslated region (3'-UTR) of the target mRNA in a manner that is not fully complementary. miRNAs are involved in biological processes, such as cell proliferation, apoptosis, growth, and metabolism (Friedman et al., 2009), and play an important regulatory role in cancer, cardiovascular diseases, autoimmune diseases, and other diseases (van Rooij et al., 2006; Dalmay, 2008; Tang et al., 2009).

Using the predictions from a bioinformatics database, we screened out 16 miRNA molecules that might be used to directly target and inhibit MCP1. Sequence analysis revealed two binding sites in miR-27b and the MCP1 3'-UTR. The literature reports that miR-27b affects the function of MCP1 by acting on certain target genes in myocardial cells (Chinchilla et al., 2011; Wang et al., 2012), but there have been no reports on whether miR-27b downregulates the expression of MCP1 and is involved in the occurrence and development of VMC. 
Therefore, in this study, we used IL-17 to induce the upregulation of MCP1 expression, then up-regulated the content of miR-27b by transiently transfecting $\mathrm{H} 9 \mathrm{C} 2$ cells with miR-27b mimics. We investigated the expression of MCP1 to determine the impact of miR-27b, thereby providing a new explanation for the pathogenesis of VMC and a new biological therapy for the prevention and treatment of myocarditis.

\section{MATERIAL AND METHODS}

\section{Groups}

To study the influence of IL-17 on the expression of MCP1, H9C2 cells were divided into six groups. IL-17 $(50 \mathrm{mg} / \mathrm{mL})$ (Axygen Scientific Inc., USA) was added to each group, which was cultured in a $\mathrm{CO}_{2}$ incubator (Heraeus $\mathrm{GmbH}$, Hanau, Germany) at $37^{\circ} \mathrm{C}$ for 0 , $2,4,8,12$, and $24 \mathrm{~h}$, and then investigated. The supernatant from each experimental group was collected and stored at $-70^{\circ} \mathrm{C}$ until required for the MCP1 protein test. The total RNA of H9C2 myocardial cells (Boyan Biotechnology Co., Ltd., Shanghai, China) was extracted for detection of MCP1 mRNA.

We investigated the effect of miR-27b in $\mathrm{H} 9 \mathrm{C} 2$ cells after transfection with miR$27 \mathrm{~b}$ mimics. Three groups were used: a transfection group with miR-27b mimics; an miRNA negative control group; and a mock group. We used $2 \mathrm{~mL} \mathrm{10 \%} \mathrm{fetal} \mathrm{bovine} \mathrm{serum} \mathrm{in} \mathrm{Dulbecco's}$ modiðed Eagle's medium (DMEM) (HyClone; GE Healthcare Life Sciences, Logan City, UT, USA) and $200 \mu \mathrm{L}$ serum-free medium in the control group.

To investigate the influence of miR-27b on IL-17-induced MCP1 expression in H9C2 cells, four groups were used: an miR-27b mimics + IL-17 (Shanghai Jima Gene Biotech Co., Shanghai, China) group; an miRNA negative control + IL-17 group, an IL-17 group; and a control group. After transfection with miRNA-oligo for $48 \mathrm{~h}$, IL-17 was added to the miR$27 \mathrm{~b}$ mimics intervention group, the miRNA negative control group, and the IL-17 group, and the groups were investigated after $4 \mathrm{~h}$. We added $2 \mathrm{~mL} \mathrm{10 \%} \mathrm{fetal} \mathrm{bovine} \mathrm{serum} \mathrm{DMEM}$ medium and $200 \mu \mathrm{L}$ serum-free medium to the blank control well. The supernatant from each experimental group was collected and stored at $-70^{\circ} \mathrm{C}$ until required for the $\mathrm{MCP} 1$ protein test. The total RNA of the H9C2 myocardial cells was extracted for the detection of mRNA.

\section{Cell culture and subculture}

The flasks were removed from the incubator and the medium was drained. D-Hank's solution and $2 \mathrm{~mL} \mathrm{0.25 \%} \mathrm{trypsin-ethylenediaminetetraacetic} \mathrm{acid} \mathrm{(EDTA)} \mathrm{(Beijing} \mathrm{Solarbio}$ Science and Technology Company, Beijing, China) were added to each culture flask, followed by washing twice with trypsin and discarding until the cells separated. Digestion was terminated by adding DMEM/high glucose cell culture medium to the flasks and draining the medium. A cell suspension was made by adding the solution $(5 \mathrm{~mL})$ to the flasks, pipetting 50-100 times, then inoculating 1.0-1.5 x 106 $\mathrm{H} 9 \mathrm{C} 2$ cells into 6-well plates containing $2 \mathrm{~mL}$ medium, followed by transfection after $24 \mathrm{~h}$ when the cells reached 30$50 \%$ confluency.

After subculture or inoculation, we observed the growth condition and confluency of the $\mathrm{H} 9 \mathrm{C} 2$ cells under an inverted microscope. The fluorescent expression was observed after transfection for 4-6 $\mathrm{h}$ in order to determine the efficiency of transfection. 


\section{Transfection}

siRNA-Mate ${ }^{\mathrm{TM}}(10 \mu \mathrm{L})$ was added to the mixture of $11 \mu \mathrm{L} 1 \mu \mathrm{M}$ miRNA-oligo (Shanghai Jima Gene Biotech Co., Shanghai) and $180 \mu \mathrm{L}$ serum-free DMEM high glucose medium, which was mixed by pipetting. After centrifuging gently at room temperature for $10 \mathrm{~min}$, the miRNA-oligo-siRNA-Mate ${ }^{\mathrm{TM}}$ complex was formed. The complex was added dropwise to a 6-well cell culture plate with replaced medium, mixed by agitating, and placed in a $\mathrm{CO}_{2}$ incubator at $37^{\circ} \mathrm{C}$. Transfection efficiency was detected after $4-6 \mathrm{~h}$, and the entire operation was protected from light.

\section{Expression of miR-27b and MCP1 mRNA in H9C2 cells detected by quantitative reverse transcription polymerase chain reaction (qRT-PCR)}

The total RNA in each group was extracted using TRIzol reagent, and the concentration and mass of RNA were detected using a spectrophotometer. The integrity of the RNA was determined by agarose gel electrophoresis. RNA $(1 \mu \mathrm{L})$ was taken for the reverse transcription reaction. A SuperQuick RT cDNA first strand synthesis kit (Beijing Kangwei Century Biotechnology Co., Ltd., Beijing, China) was used according to the manufacturer operating instructions, and the reaction system was vibrated and centrifuged briefly, then incubated at $37^{\circ} \mathrm{C}$ for $15 \mathrm{~min}$ and $85^{\circ} \mathrm{C}$ for $5 \mathrm{~s}$. After reaction, the system was centrifuged briefly again and placed on ice to cool. Complementary DNA (cDNA) synthesized by reverse transcription was used as the template for qRT-PCR amplification. The MCP1 primer sequences were F: 5'-TCCACCACTATGCAGGTCTC-3', R: 5'-TGGACCCATTCCTTATTGGG-3'. The $\beta$-actin primer sequences were F: 5'-CACCCGCGAGTACAACCTTC-3', R: 5'-CCCATACCCACCATCACACC-3'. The reaction conditions for SYBR Green quantitative PCR were: pre-denaturation at $95^{\circ} \mathrm{C}$ for $10 \mathrm{~min}$; followed by 40 cycles of denaturation at $95^{\circ} \mathrm{C}$ for $15 \mathrm{~s}$, annealing at $60^{\circ} \mathrm{C}$ for $20 \mathrm{~s}$, and extension at $72^{\circ} \mathrm{C}$ for $20 \mathrm{~s}$. The melting curve was investigated immediately after the reaction was completed using the following regimen: $95^{\circ} \mathrm{C}$ for $15 \mathrm{~s}, 60^{\circ} \mathrm{C}$ for $1 \mathrm{~min}, 95^{\circ} \mathrm{C}$ for $15 \mathrm{~s}$, and $60^{\circ} \mathrm{C}$ for $15 \mathrm{~s}$. Real-time quantitative PCR was conducted using Roche 480II equipment (Roche Company, Basle, Switzerland). The cycle threshold $(\mathrm{Ct})$ values for each well were determined and the $\Delta \Delta \mathrm{Ct}$ values were calculated using the following equation: $\Delta \Delta \mathrm{Ct}=\left(\mathrm{Ct}_{\text {sample }}-\mathrm{Ct}_{\text {reference gene }}\right)-\left(\mathrm{Ct}_{\text {negative control }}-\mathrm{Ct}_{\text {reference gene }}\right)$. After standardization, the $2^{(\Delta \Delta \mathrm{Ct})}$ values were calculated, which represented the value of the initial copy number of the sample.

\section{Changes of MCP1 protein in supernatant of $\mathrm{H} 9 \mathrm{C} 2$ cells detected by enzyme-linked immunosorbent assay (ELISA)}

After centrifuging at $3000 \mathrm{rpm}$ for $10 \mathrm{~min}$, the supernatants were collected for testing. A standard well, a blank control well, and a sample well were designated. A standard dilution $(100 \mu \mathrm{L})$ was added to the first well, a standard dilution $(50 \mu \mathrm{L})$ was added to wells $2-6$, and for wells $1-6$, the standard concentrations were: $1600,800,400,200,100$, and $50 \mathrm{pg} / \mathrm{mL}$. Then, a $40-\mu \mathrm{L}$ sample dilution and a $10 \mu \mathrm{L}$ test sample was added to the sample wells. Horseradish peroxidase (HRP)-labeled detection antibody $(100 \mu \mathrm{L})$ was added to each well and the wells were sealed using a sealing plate membrane, then incubated at $37^{\circ} \mathrm{C}$ for $1 \mathrm{~h}$ and protected from light. The chromogenic reagent was added after washing five times. The optical density (OD) 
value of each well was measured at $450 \mathrm{~nm}$ wavelength using a Microplate reader (Finland Leibo Corporation), and the concentration of MCP1 in the test samples was calculated from the standard curve.

\section{Statistical analysis}

The SPSS17.0 software was used for analysis of the experimental data, and the results are reported as means \pm standard deviation. Comparison between multiple sets of measurement data was carried out by one-way analysis of variance (ANOVA). The least significant difference (LSD) $t$-test was used for data analysis between groups, and $\mathrm{P}<0.05$ was considered statistically significant.

\section{RESULTS}

\section{Effect of IL-17 on the expression of MCP1 in H9C2 myocardial cells}

IL-17 $(50 \mathrm{ng} / \mathrm{mL})$ was used to stimulate the H9C2 cells, and the expression of MCP1 mRNA increased for $0-4 \mathrm{~h}$, peaked at $4 \mathrm{~h}$, then gradually declined. The differences in the relative expression of MCP1 mRNA at the time-points were statistically significant $(\mathrm{P}<0.05$, Figure 1A). Under the effect of IL-17, the expression of MCP1 protein in the H9C2 cell culture supernatant increased gradually over $0-24 \mathrm{~h}$. The differences in the protein concentrations at each time-point were statistically significant $(\mathrm{P}<0.05$, Figure 1B).
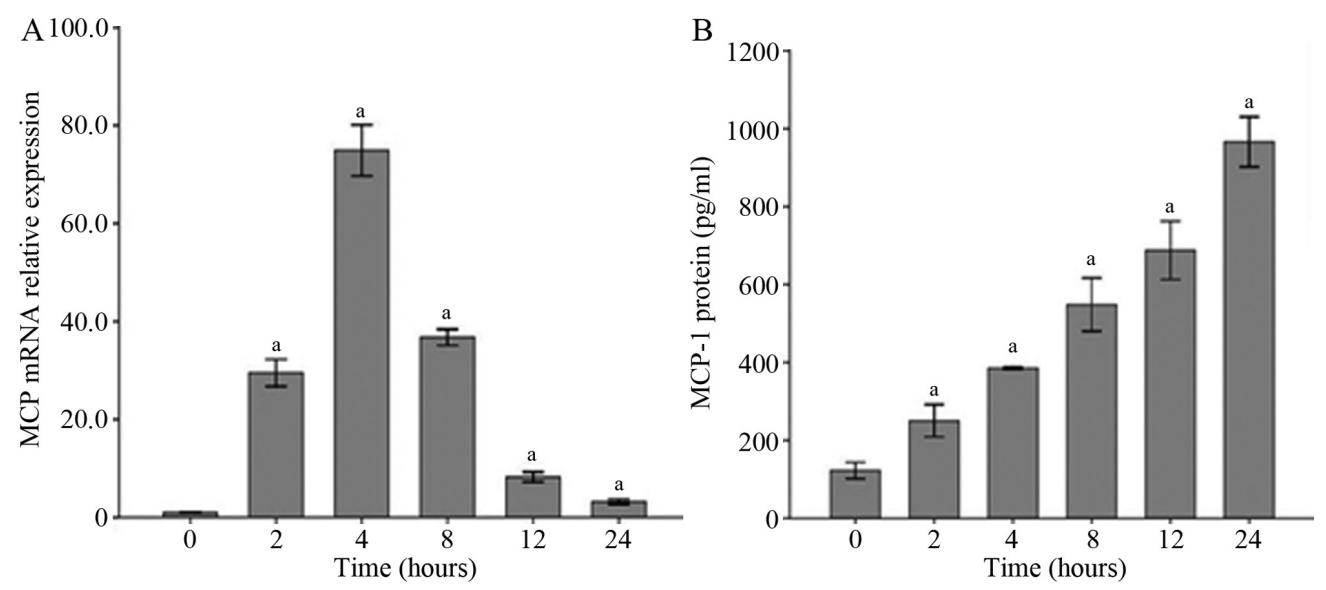

Figure 1. Effect of $50 \mathrm{ng} / \mathrm{mL}$ IL-17 on the expression of MCP1 in $\mathrm{H} 9 \mathrm{C} 2$ cells at different time-points. A. Relative expression levels of MCP1 mRNA. B. Expression of MCP1 protein. ${ }^{a} \mathrm{P}<0.05 v s$ control group.

\section{Analysis of miR-27b in H9C2 cells after transfection with miR-27b mimic}

There was no statistically significant difference in the relative miR-27b expression between the negative control and mock groups in the H9C2 cells, as detected by RT-PCR (P $>0.05)$. However, compared with the negative control group, the miR-27b mimic-transfected group showed a significant increase in relative miR-27b expression $(\mathrm{P}<0.01$, Figure 2$)$. 


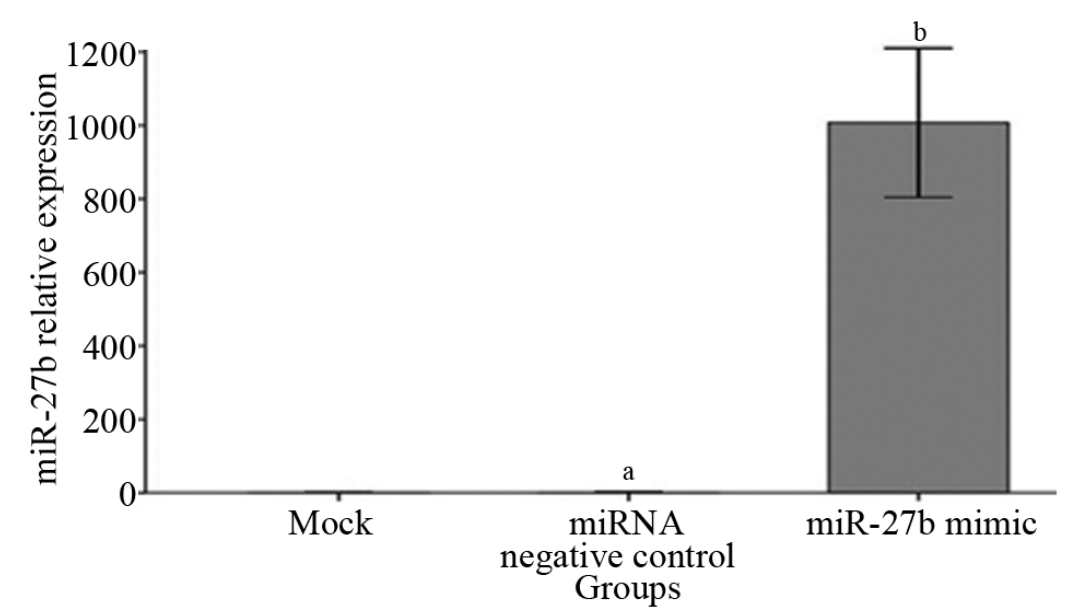

Figure 2. Relative expression levels of miR-27b in the mock group, the control group, and the miR-27b mimic group. ${ }^{\mathrm{a}} \mathrm{P}>0.05,{ }^{\mathrm{b}} \mathrm{P}<0.01$ vs blank control group.

\section{Effect of miR-27b mimic on the expression of IL-17-induced MCP1 after transfection into H9C2 cells}

Compared with the control group, the relative expression of MCP1 mRNA in the IL-17 group was significantly elevated, and the expression of MCP1 protein increased; the differences were statistically significant $(\mathrm{P}<0.05$, Figure 3$)$. Compared with the negative control group transfected with miRNA mimics, the relative expression of MCP1 mRNA and the expression level of protein in the IL-17 group were not significantly different $(\mathrm{P}>0.05$, Figure 3). Compared with the negative control group transfected with miRNA mimics, the relative expression of MCP1 mRNA in the group transfected with the miR-27b mimic was significantly reduced, and the expression level of protein was up-regulated; the differences were statistically significant $(\mathrm{P}<0.01$, Figure 3$)$.
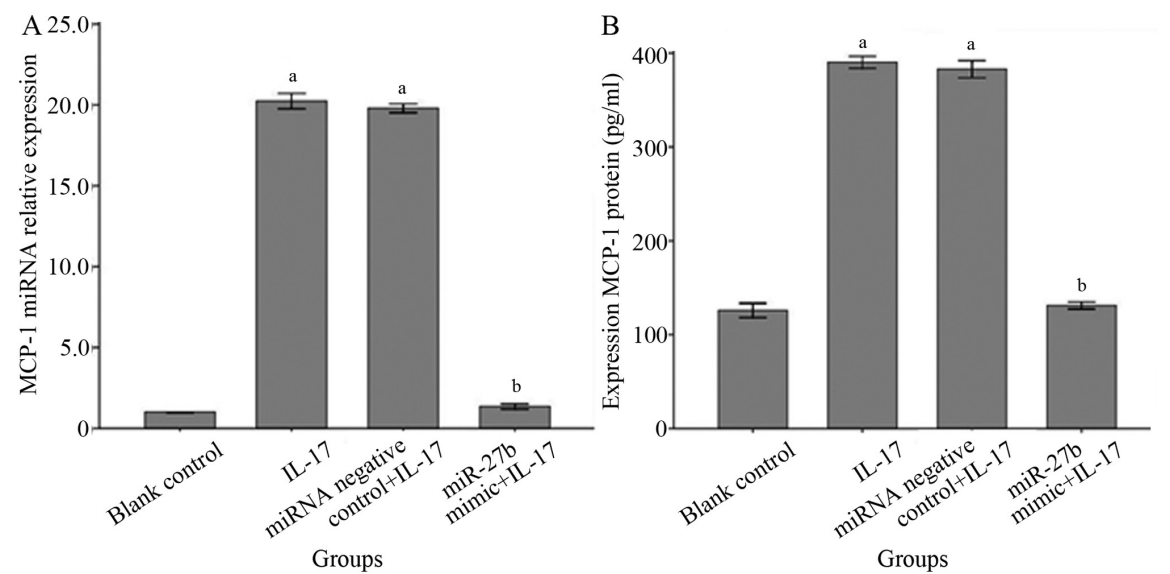

Figure 3. Expression of MCP1 in the IL-17-induced H9C2 cells transfected with miR-27b. A. The expression of MCP1 mRNA. B. The expression of MCP1 protein. ${ }^{a} \mathrm{P}<0.01,{ }^{b} \mathrm{P}>0.05$ vs blank control group. 


\section{DISCUSSION}

IL-17 is an important inflammatory mediator and can mediate inflammatory infiltration and tissue injury by inducing various inflammatory cytokines (Komiyama et al., 2006; Dallenbach et al., 2015). Rangachari et al. (2006) confirmed that IL-17 plays an important role in the process of experimental autoimmune myocarditis. Our previous study found that IL-17 can upregulate the expression of MCP1 in primary myocardial cells.

Our findings in H9C2 myocardial cell lines showed that the expression of MCP1 mRNA peaked at $4 \mathrm{~h}$, then began to decline, and the expression of MCP1 mRNA at $24 \mathrm{~h}$ was still higher than at $0 \mathrm{~h}$. In contrast, the expression level of MCP1 protein in the H9C2 cell supernatant increased gradually over 0-24 h. This unsynchronized phenomenon may be due to the accumulation of protein and the degradation of mRNA over time. IL-17 mainly acts through a series of signaling pathways, and the literature reports that IL-17 exerts its biological function by the activation of signaling molecules, such as NF-kB and MAP kinases, ERK1 and ERK2, JNK, and P38 (Lubberts et al., 2005; Dong et al., 2013). On the basis of analyzing the sequences of MCP1, Lee et al. (2002) and Dong et al. (2014) found that NF-kB-specific binding sites exist on the upstream MCP1 promoter; these sites are necessary to promote the transcription of MCP1. Thus, we speculated that IL-17 could start the transcription and up-regulate the expression of MCP1, possibly through one or more signaling pathway, but the specific mechanism remains unclear. There has been extensive research into microRNAs in recent years. miRNAs regulate cell biological function through the negative regulation of target genes. In this study, by detecting the effect of miR-27b on the expression of IL-17-induced MCP1 in H9C2 cells, we determined whether miR-27b can down-regulate the expression of MCP1 induced by IL-17.

The results showed that, compared with the control group, the relative expression of MCP1 mRNA and the expression level of protein in the IL-17 group increased significantly, and after overexpression of miR-27b induced by IL-17 in $\mathrm{H} 9 \mathrm{C} 2$ cells, the relative expression of MCP1 mRNA and the expression level of protein were significantly reduced; the differences were statistically significant $(\mathrm{P}<0.01)$. According to the results, overexpression of miR-27b may indeed down-regulate the expression of MCP1 mRNA and protein, which may be due to the targeted binding of miR-27b and MCP1 mRNA. This may account for the different degrees of silencing or degradation, which result in the decreased expression of MCP1 mRNA, thereby affecting the expression of MCP1 protein. It may also be the reason for the combination of the miR-27b mimic and NF- $\kappa \mathrm{B}$, inhibiting the activation of NF- $\kappa \mathrm{B}$ and leading to the decrease in expression of MCP1 activated by the NF- $\mathrm{kB}$ signal transduction pathway (Thulasingam et al., 2011). In addition, we do not exclude the possibility that the combination of the miR-27b mimic and the upstream regulatory genes of MCP1 could down-regulate the expression of MCP1 indirectly. No matter which way is adopted, miR-27b may lead to the decreased expression of MCP1 mRNA, which could provide a new biological therapy for the prevention and treatment of viral myocarditis.

\section{Conflicts of interest}

The authors declare no conflict of interest.

\section{ACKNOWLEDGMENTS}

Research supported by Henan Province Research Project Grant (\#0496060902). 


\section{REFERENCES}

Chinchilla A, Lozano E, Daimi H, Esteban FJ, et al. (2011). MicroRNA profiling during mouse ventricular maturation: a role for miR-27 modulating Mef2c expression. Cardiovasc. Res. 89: 98-108. http://dx.doi.org/10.1093/cvr/cvq264

Dallenbach K, Maurer P, Röhn T, Zabel F, et al. (2015). Protective effect of a germline, IL-17-neutralizing antibody in murine models of autoimmune inflammatory disease. Eur. J. Immunol. 45: 1238-1247. http://dx.doi.org/10.1002/ eji.201445017

Dalmay T (2008). MicroRNAs and cancer. J. Intern. Med. 263: 366-375. http://dx.doi.org/10.1111/j.13652796.2008.01926.x

Dong N, Chang L, Wang B and Chu L (2014). Retinal neuronal MCP-1 induced by AGEs stimulates TNF- $\alpha$ expression in rat microglia via p38, ERK, and NF-кB pathways. Mol. Vis. 20: 616-628.

Dong Z, Yang Y, Zhang T, Li Y, et al. (2013). siRNA-Act1 inhibits the function of IL-17 on lung fibroblasts via the NF- $\kappa B$ pathway. Respiration 86: 332-340. http://dx.doi.org/10.1159/000348403

Friedman RC, Farh KK, Burge CB and Bartel DP (2009). Most mammalian mRNAs are conserved targets of microRNAs. Genome Res. 19: 92-105. http://dx.doi.org/10.1101/gr.082701.108

Fuse K, Kodama M, Hanawa H, Okura Y, et al. (2001). Enhanced expression and production of monocyte chemoattractant protein-1 in myocarditis. Clin. Exp. Immunol. 124: 346-352. http://dx.doi.org/10.1046/j.1365-2249.2001.01510.x

Kolattukudy PE, Quach T, Bergese S, Breckenridge S, et al. (1998). Myocarditis induced by targeted expression of the MCP-1 gene in murine cardiac muscle. Am. J. Pathol. 152: 101-111.

Komiyama Y, Nakae S, Matsuki T, Nambu A, et al. (2006). IL-17 plays an important role in the development of experimental autoimmune encephalomyelitis. J. Immunol. 177: 566-573. http://dx.doi.org/10.4049/jimmunol.177.1.566

Lee SK, Kim CS, Yang WS, Kim SB, et al. (2002). Exogenous nitric oxide inhibits tumor necrosis factor-alpha- or interleukin-1-beta-induced monocyte chemoattractant protein-1 expression in human mesangial cells. Role of IkappaB-alpha and cyclic GMP. Nephron 92: 780-787. http://dx.doi.org/10.1159/000065441

Liu YY, Li YY, Wang SS and Shen Y (2012). [Effect of IL-17 on the expression of monocyte chemoattractant protein-1 in the cardiac myocytes]. Xibao Yu Fenzi Mianyixue Zazhi 28: 163-166.

Lubberts E, Koenders MI and van den Berg WB (2005). The role of T-cell interleukin-17 in conducting destructive arthritis: lessons from animal models. Arthritis Res. Ther. 7: 29-37. http://dx.doi.org/10.1186/ar1478

Qiu Z, Dillen C, Hu J, Verbeke H, et al. (2009). Interleukin-17 regulates chemokine and gelatinase B expression in fibroblasts to recruit both neutrophils and monocytes. Immunobiology 214: 835-842. http://dx.doi.org/10.1016/j. imbio.2009.06.007

Rangachari M, Mauermann N, Marty RR, Dirnhofer S, et al. (2006). T-bet negatively regulates autoimmune myocarditis by suppressing local production of interleukin 17.J. Exp. Med. 203: 2009-2019. http://dx.doi.org/10.1084/jem.20052222

Shen Y, Xu W, Chu YW, Wang Y, et al. (2004). Coxsackievirus group B type 3 infection upregulates expression of monocyte chemoattractant protein 1 in cardiac myocytes, which leads to enhanced migration of mononuclear cells in viral myocarditis. J. Virol. 78: 12548-12556. http://dx.doi.org/10.1128/JVI.78.22.12548-12556.2004

Shen Y, Kan QC, Xu W, Chu YW, et al. (2009). Coxsackievirus B3 infection induced viral myocarditis by regulating the expression pattern of chemokines in cardiac myocytes. Iran. J. Allergy Asthma Immunol. 8: 1-9.

Shen Y, Zhang FQ and Wei X (2014). Truncated monocyte chemoattractant protein-1 can alleviate cardiac injury in mice with viral myocarditis via infiltration of mononuclear cells. Microbiol. Immunol. 58: 195-201. http://dx.doi. org/10.1111/1348-0421.12130

Tang Y, Luo X, Cui H, Ni X, et al. (2009). MicroRNA-146A contributes to abnormal activation of the type I interferon pathway in human lupus by targeting the key signaling proteins. Arthritis Rheum. 60: 1065-1075. http://dx.doi. org/10.1002/art.24436

Thulasingam S, Massilamany C, Gangaplara A, Dai H, et al. (2011). miR-27b*, an oxidative stress-responsive microRNA modulates nuclear factor-kB pathway in RAW 264.7 cells. Mol. Cell. Biochem. 352: 181-188. http://dx.doi. org/10.1007/s11010-011-0752-2

van Rooij E, Sutherland LB, Liu N, Williams AH, et al. (2006). A signature pattern of stress-responsive microRNAs that can evoke cardiac hypertrophy and heart failure. Proc. Natl. Acad. Sci. USA 103: 18255-18260. http://dx.doi. org/10.1073/pnas.0608791103

Wang J, Song Y, Zhang Y, Xiao H, et al. (2012). Cardiomyocyte overexpression of miR-27b induces cardiac hypertrophy and dysfunction in mice. Cell Res. 22: 516-527. http://dx.doi.org/10.1038/cr.2011.132 